\begin{tabular}{l|l} 
Postprint & 1.0
\end{tabular}

Version

Journal website $\quad$ http://dx.doi.org/10.1016/i.pec.2013.01.020

Pubmed link http://www.ncbi.nlm.nih.gov/pubmed/23433778

DOI 10.1016/j.pec.2013.01.020

This is a NIVEL certified Post Print, more info at http://www.nivel.eu

\title{
Developing and administering scripted video vignettes for experimental research of patient- provider communication
}

\author{
MARIJ A. HiLlen ${ }^{\mathrm{A},}$, , LIESBETH M. VAN VLIET $^{\mathrm{B}}$, HANNEKE C.J.M. DE HAES ${ }^{\mathrm{A}}$, ELLEN M.A. \\ SMETS $^{\mathrm{A}}$ \\ a Department of Medical Psychology, Academic Medical Center, University of Amsterdam, \\ The Netherlands \\ ${ }^{b}$ NIVEL, Netherlands Institute for Health Services Research, Utrecht, The Netherlands
}

\begin{abstract}
Objective: Scripted video-vignette studies enable experimental investigation of specific elements of patient-provider communication, separating cause and effect. However, scripted video vignettes are infrequently used to this end. Resultantly, few guidelines are available for their design, development and administration. We aim to suggest guidelines enabling more informed decisions when designing and conducting these studies.

Methods: Based on the available methodological literature, we discuss methodological considerations when developing and administering scripted video vignettes.

Results: Developing and using valid video vignettes requires: (I) deciding if using video vignettes is appropriate, (II) developing a valid script, (III) designing valid manipulations, (IV) converting the scripted consultation to video, and (V) administering the videos. We provide a first checklist of the methodological considerations in each phase. Advantages and pitfalls of possible approaches are discussed.

Conclusions: No 'gold standard' exists for most methodological issues, as literature testing the consequences of different approaches is lacking. The best approach when developing and implementing video vignettes depends upon the aims and practical limitations of a particular study.

Practice implications: Our checklist may serve as a starting point for further study of scripted video vignettes methodology. More detailed methodological reporting would yield new knowledge, thus allowing the research field to progress.
\end{abstract}


Hillen, M.A., Vliet, L.M. van, Haes, H.C.J.M. de, Smets, E.M.A. Developing and administering scripted video vignettes for experimental research of patient-provider communication. Patient Education and Counseling: 2013, 91(3), 295-309

\section{BACKGROUND}

Observational research has been frequently used to investigate the effects of care providers' communication on relevant patient outcomes [1]. Such research aims to identify, categorize and quantify communication behavior [2]. Although observational research allows registering actual clinical behavior in a non-invasive manner, an important drawback is that it does not permit definitive conclusions about cause and effect [3]. Experimental methods are therefore needed. Experimentally manipulating care providers' communication behavior in clinical practice is problematic because the manipulations may expose patients to suboptimal communication. Alternatively, the impact of communication can be investigated in lab settings, by experimentally varying behavior in a hypothetical patient-provider interaction. A specific type of such experimental lab research involves scripted video vignettes.

In patient-provider communication research, scripted video vignettes have been introduced to systematically study the effects of specific communication on patient outcomes. Scripted video vignettes are short visual depictions of pre-written (hypothetical) events. Generally, multiple variations of a scripted vignette are created, depicting a consultation between care provider(s) and patient(s). Except for varying specific elements of communication, all other content of the vignettes is held constant. The role-played video vignettes are viewed by 'analog patients' (APs), who are either (former) patients, or healthy people instructed to imagine themselves in the place of the patient observed in the video [4]. After watching the video vignette(s), APs' perceptions or evaluations of specific aspects of the videotaped consultation can be assessed. Several outcome measures can be employed: (1) evaluative outcomes, such as perception of the physician [5]; [6]; [7]; [8]; [9]; [10]; [11] ; [12] or preference for a consultation style [11]; [13]; [14] ; [15]; (2) affective outcomes, such as (self-reported and/or physiological) anxiety and distress [16]; [17] ; [18]; (3) behavioral outcomes, such as intended treatment decision [13], self-disclosure [10], and compliance [7] ; [12]; and (4) cognitive outcomes, such as recall [17] ; [18].

The research field using scripted video vignettes of patient-provider communication is still in development. A review of the empirical literature revealed that only 18 experimental video-vignette studies testing the effects of physician communication have been published thus far [19] (see Table 1 for an overview). Results of these studies indicate that video vignettes allow effective manipulation of communication [7]; [20]; [21]; [22]; [23], are perceived as realistic [7]; [16]; [18]; [22] ; [24], and enable observers to immerse themselves in the situation depicted [17]; [18] ; [24]. Thus, they can yield valid and informative results. Significant effects were indeed established thus far for evaluative, affective and behavioral outcomes, and in some but not all cases for cognitive outcomes. Thus, the relative scarcity of literature seems not due to a lack of feasibility or validity of this methodology for studying patient-provider communication. An alternative explanation for the limited use of video vignettes is that researchers shy away at, or get lost in, the daunting task of creating and implementing video vignettes. Presently, no clear instructions or guidelines exist on how to deal with the many methodological issues encountered. Very little empirical evidence is available to support one approach over the other. 
We aim to advance the field by providing an overview of the methodological nivel considerations encountered in each phase of developing and implementing scripted video vignettes, and possible approaches to address these considerations. This is a first attempt to provide guidelines, as to prepare researchers for making the most appropriate choices for their specific study requirements. It may serve as a starting point for further study of the methodology itself, to enable the development of more specific guidelines and recommendations in the future.

\section{METHODS}

For our overview, we based ourselves on three sources. First, the method sections of the 18 available studies previously identified were inventoried for methodological issues, possible approaches and their rationales when developing and administering scripted video vignettes in physician-patient communication research. Second, we sought methodological literature on developing vignettes in related fields and using different designs. To that end, literature databases Pubmed, Embase, Cinahl and Psychinfo were searched using all variants of the keywords Vignettes, Methodology and Development. This search yielded three papers exclusively focussed on the advantages and challenges in the development of vignettes [25] ; [26] or on its methodological difficulties [27]. Moreover, four papers presented exceptionally elaborate, stepwise, accounts of their methodological choices during vignette development [28]; [29]; [30] ; [31]. All seven methodological articles identified in our literature search are displayed in Table 2. Third, the first and second authors (MH and LvV) supplemented the overview based on their experience with developing vignettes.

\section{[TABLE 1.] [TABLE 2.]}

Through informal discussion between all authors, the methodological issues were formalized and categorized into five phases. These phases are: (1) deciding if using video vignettes is appropriate (Phase I), (2) developing a valid script (Phase II), (3) designing valid manipulations (Phase III), (4) converting the scripted consultations to video (Phase IV), and (5) administering the videos (Phase V). All methodological considerations encountered during each of these stages are displayed in Fig. 1. Moreover, Table 1 provides an overview of the different approaches used in the 18 empirical studies published thus far, to direct readers to relevant empirical examples.

\section{[FIGURE 1.]}

\section{RESULTS}

\subsection{Phase I: deciding if using video vignettes is appropriate}

Scripted video vignettes are a suitable methodology to answer some questions, but not others. Frequently, researchers using this method have failed to justify their choice (see Table 1). Methodologically, scripted video vignettes may be most appropriate if causal relations between specific elements of communication and particular outcomes are of interest [6]; [10]; [15]; [17]; [24]. In clinical practice, specific communication elements cannot be isolated as not all behavior can be 
standardized [27]. In scripted video vignettes all elements (communication as well as context) except for the intended manipulation can, and must, be kept constant [6], allowing definitive conclusions about cause and effect. For example, specific variations in the phrasing of a diagnosis can be contrasted while the remainder of the consultation is standardized [17]. Moreover, analog patients may provide less skewed outcome ratings than are often found in clinical practice [13]; [15]. This may be because social desirability is reduced. Especially when assessing evaluative outcomes such as satisfaction and trust, patients are often hesitant to be critical of their own health care provider. In video-vignette studies, APs may be able to provide more independent ratings [19].

Ethically, for studies that investigate the effect of potentially harmful communication, scripted video vignettes provide an alternative to manipulating communication in real-life situations, especially when participants are from a vulnerable patient group [7] ; [18]. For example, in a study manipulating physicians' information giving behavior, it may be expected that a lower amount of information could negatively impact on real patients, making a lab setting more appropriate [7]. Scripted video vignettes also have their disadvantages, the most important one being their more limited ecological validity. Even maximally realistic vignettes will differ from communication as it naturally unfolds. For example, viewers cannot ask questions [18]. Consequently, not all conversational elements can be tested using video vignettes. Additionally, isolating specific communication elements means employing a reductive approach, which may oversimplify the rich and complex reality of communication [25]. For a more elaborate overview of advantages and disadvantages of using scripted video vignettes, see Van Vliet et al. [19].

\subsection{Phase II: developing a valid script}

\subsubsection{The background of the script}

A script can be written based either on literature guidelines and experience [11]; [15]; [17]; [18]; [24] or on real interactions [16] (see Table 1). Drawing from one's own experience or that of experts allows shaping of the consultation content completely according to the study requirements. It could, however, result in a less realistic script. When using real audio- or videotaped consultations as a basis, precise phrasings can be integrated verbatim into the script. This does require that the original consultations are representative of the situation aimed to be depicted.

\subsubsection{The proportion of the consultation scripted}

The script can reflect a whole consultation or, alternatively, encompass part(s) or an abridged version of the consultation (see e.g., [15] ; [17]). Abridged scripts may come at the expense of ecological validity. They will, however, reduce the time and effort needed to create and administer the videos. Moreover, if manipulations are subtle and small, their impact may be larger when using shorter videos, as participants are allowed to focus more closely [27]. For example, in a study investigating the impact of oncologist communication on patients' trust, the planned manipulations were small, encompassing only a few sentences. Therefore, the script was cut down to last only $5 \mathrm{~min}$, while the researchers made sure that essential elements of the consultation were preserved (Hillen et al., in preparation). In the studies published thus far (see Table 1), vignettes were usually shorter than real consultations (lasting on average approximately $7 \mathrm{~min}$, range $2-19 \mathrm{~min}$ ), but 
Hillen, M.A., Vliet, L.M. van, Haes, H.C.J.M. de, Smets, E.M.A. Developing and administering scripted video vignettes for experimental research of patient-provider communication. Patient Education and Counseling: 2013, 91(3), 295-309

included at least their basic elements, e.g., diagnosis, treatment, and prognosis [10]; [13]; [16]; [22]. Others focused on one or two segments of the consultation only [17]; [20].

\subsubsection{Establishing realism}

Realism of the script can be evaluated by consulting different experts, such as health care professionals, patients, and/or researchers from the same field. These experts can comment upon the script's realism, regarding both communicative behavior and context [12] ; [24]. Additionally, professional film makers can advise on script fluidity [31]. As Table 1 shows, consultation of experts at this stage is not commonly performed. In some studies, however, experts consulted at other development stages may have been involved during script development as well.

\subsubsection{Developing an introduction}

An introduction to familiarize participants with the observed situation can be presented in several ways: face to face by the researcher [18], written on paper [17] ; [24] or on the video screen [12], read aloud by voice-over (Hillen et al., in preparation), or enacted by the characters from the video consultation [11] (see Table 1). In the latter case, the patient and/or care provider might introduce themselves to the camera, as if interviewed in documentary-style.

An advantage of using a video introduction is that it allows participants to grow accustomed to multiple facets of the subsequent video. They can process basic elements, such as the setting, characters' appearance, allowing them to focus more on the communication elements of the subsequent experimental video. A video introduction in documentary-style may have a relatively strong emotion-inductive effect [32]; [33] ; [34], creating empathy and emotional involvement with the patient depicted, which may or may not be desirable depending on study aims. A disadvantage of emotion-induction is that it is difficult to assess how and to what extent the introductory video influences participants' subsequent perception. Therefore, if the introduction is intended to be purely informative, a written introduction or audio introduction by voice-over is preferred.

\subsection{Phase III: designing valid manipulations}

\subsubsection{Operationalizing manipulations}

When a basic script is ready, variations of the script need to be created, requiring careful consideration of both the operationalization of the independent variable(s) and the ideal number of manipulation levels [27]. Elementary factors, such as 'warning before diagnosis' [17], or 'arm position' [5] allow for straightforward operationalization. Many studies, however, aim to manipulate less clearly defined concepts (see Table 1), e.g., 'patient-centered communication' [12]; [13] ; [15] or 'the expression of compassion' [16]. Operationalizing such concepts requires more elaborate motivation. To ensure internal validity, a possible effect should be attributable only to a manipulation of the variable of interest. Resultantly, studies manipulating very specific, isolated, behaviors are more powerful than those combining several behaviors into one manipulation. Experts can be consulted at this stage to ensure that the proposed manipulations are distinguishable, yet not caricatures of normal practice [27]. Researchers have based the translation of elusive 
Hillen, M.A., Vliet, L.M. van, Haes, H.C.J.M. de, Smets, E.M.A. Developing and administering scripted video vignettes for experimental research of patient-provider communication. Patient Education and Counseling: 2013, 91(3), 295-309

concepts in manipulations on (empirical) literature [7]; [12]; [13]; [24] ; [35], and/or qualitative exploration among the target group [7]; [13] (see Table 1).

A final consideration is how many levels of the variable of interest are to be presented: two (e.g., standard vs. enhanced expression of empathy [16]) or three or more (e.g., patient-, vs. disease- vs. emotion-centered consultation style [8]). More levels allow the identification of optimal levels of performance, in case of a nonlinear relationship. However, including more than two levels requires a larger sample size to demonstrate effects with sufficient power. Moreover, if more than one variable is manipulated, sufficient vignette versions should be created to encompass all possible combinations of the manipulations [27].

\subsubsection{The verbal and/or nonverbal nature of the manipulations}

Manipulations may encompass verbal or nonverbal elements, or both. It may be difficult and even artificial to distinguish verbal from nonverbal communication in manipulations, because they are so tightly linked [36]. Including both verbal and nonverbal elements in manipulations could thus enhance realism and ensure ecological validity. For example, in one study varying patient-centered communication, the manipulation encompassed both verbal and nonverbal behaviors, as the authors argued that patient-centered communication behaviors would unlikely occur in isolation [12]. Most frequently, verbal and nonverbal behaviors are manipulated simultaneously (see Table 1).

The downside of this approach, however, is that it reduces the possibility of causal attribution. If both verbal and nonverbal aspects are varied one cannot be sure whether a possible effect was caused by what someone said or how the person said it. To disentangle verbal from nonverbal effects, in a study manipulating only nonverbal behavior, video vignettes were presented to participants without sound [5]. Ideally, all combinations (i.e., verbal and nonverbal, only verbal, only nonverbal, and neither verbal nor nonverbal) would be included into the design as separate conditions. In reality, however, this may not always be feasible, since it requires more video versions as well as a larger sample size. Therefore, researchers will have to weigh ecological validity against causal attribution.

\subsubsection{Compensating for duration differences}

Including manipulations into the basic script will almost invariably result in duration differences between different versions. Time may then account for a possible effect instead of the manipulation. Duration differences can either be compensated for, or accepted. Compensation may include adding 'fillers' to the script, i.e., segments of communication not containing significant content. Alternatively, the actors can alter dialog pace. Both options, however, have similar drawbacks. First, it may be more difficult to keep the script realistic when using fillers or altering dialog pace, and second, one can never rule out that the 'filler' produces its own effect, thus becoming a manipulation in itself. Alternatively, it can be argued that duration differences are characteristic of real consultations. For example, in practice, a consultation with a more empathic physician might last longer [37]. This rationale has previously motivated researchers to retain small duration differences between different conditions (e.g., see [12]). No studies reported compensating for duration differences between vignette versions (see Table 1). 
Hillen, M.A., Vliet, L.M. van, Haes, H.C.J.M. de, Smets, E.M.A. Developing and administering scripted video vignettes for experimental research of patient-provider communication. Patient Education and Counseling: 2013, 91(3), 295-309

\subsection{Phase IV: converting the scripted consultation to video}

\subsubsection{Choosing appropriate actors}

To play the script characters, either real care providers [5]; [8]; [16]; [17] or professional actors [7]; [10]; [11]; [12]; [13]; [15]; [21]; [22]; [24] can be recruited (see Table 1). Real care providers are chosen because they may portray their roles most realistically. Moreover, they are likely to have a natural way of expressing and using medical language. On the other hand, the design of a vignette study requires actors to precisely adhere to the script, and to repeatedly play several slightly different versions of the same script. This may be impossible for care providers. They may be inclined to stick to their usual consultation style. Both for adhering to a script, and for replicating and portraying different styles, professional actors may be better equipped.

An additional consideration is the appearance of the care provider or patient to be portrayed. Their age, gender and ethnicity, as well as their attire and the room furnishing will inevitably impact on participants' perception. For the care provider role, researchers might select an actor with prototypical age and gender, to enhance viewers' perception of reality. For the patient role, identification by as many participants as possible optimizes external validity. If, for example, analog patients are sampled from a large age range, a middle-aged video patient may enable maximal identification by most participants. Considerations regarding appearance of the characters may also depend on the precise research question. Previous studies have provided no or limited information on characteristics of the actors or professionals who played their vignettes, with some exceptions [10]; [11]; [12] (see Table 1).

\subsubsection{Determining the camera perspective}

The camera perspective impacts on viewers' perception of a video [38], and could thus contribute to the vignettes' external validity. The camera may either show only what the patient views (i.e., facing the care provider), or alternate between the patient's and the care provider's point-of-view (POV). Using only the patient's POV [10]; [12], the patient is not visible, or only over the back of the shoulder (see Fig. 2 A). The care provider faces the camera, gazing into it directly (if the patient is not visible), or slightly right or left of it (if the patient is viewed over the shoulder). When both viewpoints are used, the patient's POV alternates with the care provider's POV, possibly using overview shots of the setting additionally (see Fig. 2B). Using this approach, the patient is clearly identifiable, unlike when only the patient's POV is used.

\section{[FIGURE 2]}

It has been argued that if the patient is not visualized, viewers will instead infer the patient's feelings themselves, invoking empathic involvement [39]. Others argue that the two approaches invoke different types of empathy: alternating views create 'embodied empathy', i.e., experiencing the bodily and affective feelings of the observed patient, whereas using only the patient's POV is thought to create 'imaginative empathy' in viewers [5]; [10]; [11]; [12]; [17]; [22] (see Table 1). Such imagination is used to enact the patient's mental experience [38]. This distinction has also been labeled differently, as 'perspective taking', i.e., imagining 
Hillen, M.A., Vliet, L.M. van, Haes, H.C.J.M. de, Smets, E.M.A. Developing and administering scripted video vignettes for experimental research of patient-provider communication. Patient Education and Counseling: 2013, 91(3), 295-309

experiencing the emotions of the video character, versus 'empathy', i.e., imagining what the video character feels like [40]. A disadvantage of hearing but not or barely seeing the patient is that it may be alienating to viewers. Moreover, to achieve emotion induction and 'embodied empathy' among participants, alternating views may be most appropriate, as they allow close-ups of the patient and care provider at crucial (emotional) moments.

Finally, the choice of camera viewpoint has practical consequences for editing. Alternating viewpoints allows flexible cutting between different takes. The patient's POV, on the other hand, dictates either very long takes or a very fluent transition of one shot into the other.

\subsubsection{Pilot-testing the videos}

Pilot-testing of the videos is not restricted to one specific development phase; it can be used to test the basic script, the manipulations, and/or the eventual videorecordings. Thus, pilot-testing may serve several purposes: it can enhance internal validity, by establishing manipulation success, and external validity, by investigating realism and participants' involvement in the videos. Peer researchers, potential participants, and experts may be involved. The extent and focus of pilot-testing varies strongly between published studies, and is often not clearly reported (see Table 1).

To test realism, questions used are 'I think these films are realistic' [18], or 'As a portrayal of a doctor-patient relationship, this videotape is believable' [7]. To assess manipulation success, pilot participants can be asked to score the script or video characters on the manipulated variable, using a variety of adjectives. For example, in a study manipulating a directive versus a shared decision making style, pilot participants were asked to score both versions on power, authority, directing, sharing, cooperation, negotiation, and one-sidedness [20]. Involvement has been tested by asking how well participants were able to put themselves in the scene or imagine what the video-patient is going through [7] ; [18]. Alternatively, a validated scale assessing 'transportation skill', i.e., viewers' absorption into a story, might be used [41].

More extensive pilot-testing further on in the development process will yield more informative results. Yet, at that stage adjusting the video vignettes will be more expensive and time-consuming. Similarly, using a variety of pilot participants, e.g., both clinicians and patients, will better ensure that realism, involvement and successful manipulation are reached. Because of budget or time constraints, researchers may need to adopt a middle course between optimizing the quality and effectiveness of their vignettes, and remaining within the range of what is practically possible.

\subsection{Phase V: administering the videos}

\subsubsection{Choosing viewers}

Viewers in video-vignette studies, i.e., analog patients (APs), can be actual or former patients [6]; [10]; [12]; [15]; [20]; [22], healthy participants [7]; [8]; [9]; [11]; [14]; [17]; [18]; [21]; [24]; [42], or all three [13] ; [16] (see also [19]). Sampling choices have seldom been motivated by researchers (see Table 1). Proponents of involving actual or former patients as APs believe this will enhance external validity [12]. Healthy participants may be recruited out of convenience, because it is considered 
Hillen, M.A., Vliet, L.M. van, Haes, H.C.J.M. de, Smets, E.M.A. Developing and administering scripted video vignettes for experimental research of patient-provider communication. Patient Education and Counseling: 2013, 91(3), 295-309

more ethical, or because researchers are interested in their perceptions specifically [8]. Evidence thus far indicates that there is little distinction between perceptions and evaluations of patients and healthy participants, justifying the use of the latter [13]; [16]. When involving healthy participants, matching them with the patient population of interest, e.g., in age and gender, has been suggested to improve external validity [25].

The choice of participants will also affect choices regarding the vignettes development. For example, healthy participants may be less familiar with the situation depicted in the video, requiring a different introduction than patients.

\subsubsection{Arrangement of the setting}

The viewing location and its arrangement may impact on APs' ability to immerse themselves in the observed consultation. It can be argued that the more the setting resembles the observed consultation, the better observers will be able to identify with the situation. This may motivate researchers to equip a (medical) consultation room as viewing location. Alternatively, maximal 'absorption' into the story might be achieved by creating a more cinematic setting, including an obscured room. The video and audio equipment should be of good enough quality to allow participants to immerse, including a monitor that depicts the video character at a size comparable to real life. Whether and how these context factors actually impact on patients' perception has, to the best of our knowledge, not been empirically tested. Detailed reports of viewing location or equipment are lacking in the current studies (see Table 1).

Participants can view the vignettes either in private [9]; [10]; [12]; [17]; [18]; [22] or in groups [7]; [8]; [14]; [16]; [20]; [24]. If researchers aim to create viewing conditions similar to the observed consultation, viewing in private may be preferable. Viewing the vignettes in groups can hamper participants' ability to immerse in the observed consultation. When in groups, people may use certain emotion regulation strategies, such as distraction, which are not used when alone [43]. This is undesirable when assessing an affective outcome measure, such as anxiety. For evaluative outcomes as well, group processes may impact on patients' personal ratings. Such emotion regulation might be reduced by creating 'cinematic' viewing conditions (including a large screen and darkness) during group viewings. Advantages of group viewings are that they are more efficient. Moreover, they enable organized group discussions after viewing.

\subsubsection{Determining the number of videos per viewer}

APs can be shown one vignette version [6]; [7]; [8]; [9]; [10]; [12]; [16]; [17]; [18]; [21]; [22]; [24], or several versions [5]; [11]; [13]; [14]; [15]; [20]. Showing more than one video to each viewer yields more observations, which will increase statistical power. Second, it induces contrast, thus allowing participants to compare videos [44]. A drawback is that showing several vignettes to the same participant will introduce a second level of analysis, as observations are correlated, thereby complicating statistical analyses. Moreover, possible order effects need to be accounted for in the design and analysis phase. Third, participants may lose their ability to distinguish between versions after seeing too many similar vignettes. Also, information from previous observations may interfere with subsequent ones. Using cognitive outcomes, such as recall, may not be feasible with multiple viewings. To 
Hillen, M.A., Vliet, L.M. van, Haes, H.C.J.M. de, Smets, E.M.A. Developing and administering scripted video vignettes for experimental research of patient-provider communication. Patient Education and Counseling: 2013, 91(3), 295-309

reduce 'blurring' of the different videos and potential learning effects, a distraction task can be provided to APs between viewings. Alternatively, the time period between the videos can be prolongated. Neither of these strategies against blurring effects was reported thus far (see Table 1).

\subsubsection{Informing and/or debriefing viewers}

Well-constructed video vignettes should not be distinguishable from video recordings of real medical consultations. This poses a dilemma for researchers: to what extent are APs informed about the fact that the vignettes are simulated? If viewers expect to be watching a real consultation, they may more easily identify with the patient. APs can be debriefed after their participation. However, researchers or medical ethical committees may object to deceiving participants in this respect, especially since some medical consultations can have a strong emotional impact on patients. Moreover, viewers may understand that the consultations are not real when viewing a second, similar, video. As a consequence, they will view the second video less unbiased than the first. In this case, viewers may rather be informed in advance to ensure that the different observations remain comparable. Alternatively, researchers may clarify that the vignettes represent actual situations, but are enacted without the actual patients for privacy reasons. None of the published studies thus far reported the extent to which APs were informed about the acting in the videos (see Table 1).

To assess how biased participants view the vignettes, it may be relevant to assess, directly after each vignette viewing, how well they could immerse themselves in the video consultation, and how realistic they thought the videos were. Ratings of perceived realism may be used as potential confounders in analysis [21], although no empirical studies reported on doing so (see Table 1).

\section{DISCUSSION AND CONCLUSION}

\subsection{Discussion}

We have provided an overview of the various methodological considerations when conducting experimental research using scripted video vignettes to study patientprovider communication. For each phase of development and implementation we discussed limitations and advantages of possible approaches. Our overview can be helpful for making more informed methodological decisions and writing more standardized and detailed methods sections in future articles.

Overall, no gold standard exists for how best to tackle many of the methodological issues. Many of the published studies failed to report or justify a number of their choices. There is little empirical evidence for the exact effects of the various possible approaches. Consequently, it is generally not possible to provide evidence-based recommendations. Instead, we described the advantages and disadvantages of possible approaches, based on the existing literature and our own experience. In the present paper, our focus was on the use of video vignettes within the healthcare setting testing the effects of communication on patients. However, vignettes have been employed in a wider range of research topics and study designs, both within and outside of the medical setting [25] ; [27]. The literature identified in our broader search of methodological literature on vignettes development describes 
partly similar methodological difficulties. Therefore, researchers may refer to the wider field of vignette development for inspiration.

However, guidelines for how to develop vignettes appear virtually nonexistent, not only in the doctor-patient communication research field, but over the entire range of vignette research; its methodology has not been standardized. Therefore, studies empirically investigating and comparing the consequences of different methodological approaches are needed to enable more evidence-based design choices in future research. For applying video-vignettes in experimental research of doctorpatient communication, we suggest that methodological investigation first focuses on maximizing participant identification with the video character. To that end, the relative impact of the choice of viewers, the type and content of an introduction, and different camera perspectives should be examined first. Such methodological evidence will increase the validity of eventual findings, and might lead to the creation of a guideline for optimal methodological choices.

Such research is even more relevant since making substantiated choices can prevent unnecessary investments of money and time. The whole process of developing scripted video vignettes, depending on the size of the research team and availability of resources, takes at least a couple of months, and can be very expensive. If video recording (including actors, film equipment, and crew) has to be repeated after unsatisfactory pilot-testing results, this will add significantly to time and money investments. Unnecessary other costs can be avoided if well-informed methodological decisions are made well in advance. Elaborate accounts of the proposed methodology will also facilitate the process of receiving ethical approval. Because of their unfamiliarity with video vignette methodology, ethical committees may be hesitant or overly critical in granting consent. This process will be facilitated if methodological decisions are well founded.

Methodological choices eventually made should be strongly guided by the study aims and outcome measure(s). A study assessing patients' trust in a physician requires a different methodological approach than one assessing recall accuracy or signs of distress. If, for example, emotions are the main outcome, one needs to realize that particular content beyond manipulation can unintentionally evoke emotions.

This paper has some limitations. First, our overview of different possible methodological approaches was based on a limited body of literature. This was unavoidable, as methodological literature on video vignette development is scarce. Second, although we elaborately searched the broader range of literature of vignette development, this paper was not intended as a systematic review but as a practical tool. Therefore, our broader literature overview may not be fully exhaustive. Concluding, our paper should be viewed as a starting point rather than a definitive overview, upon which future research can build.

\subsection{Conclusion}

Development and administration of scripted video vignettes for experimental research on patient-provider communication is a methodological area still in development. No 'gold standard' exists for most methodological issues encountered when conducting this type of research, as literature testing the consequences of different approaches is lacking. Methodological literature from related research fields can be consulted, but equally lacks standardization. The best approach when 
Hillen, M.A., Vliet, L.M. van, Haes, H.C.J.M. de, Smets, E.M.A. Developing and administering scripted video vignettes for experimental research of patient-provider communication. Patient Education and Counseling: 2013, 91(3), 295-309

developing and implementing video vignettes depends upon the aims and practical limitations of a particular study.

\subsection{Practice implications}

Our overview will hopefully enable researchers to make informed decisions that best fit their research aims while keeping in mind practical limitations. Fig. 1 can be used as a checklist for researchers to make sure that all relevant issues are taken into account. Moreover, the checklist provides an opportunity for standardizing methods sections of future papers. We suggest that in future scripted video-vignette studies, researchers provide detailed descriptions of their methodological choices. If necessary, these can be published in an (online) appendix. In an aligned publication, we will describe a video-vignette study's methodology in detail [45]. Such descriptions can guide future researchers, will ultimately enhance the quality of future studies using video vignettes, and thus advance the evidence in the field of medical communication.

\section{Competing interests}

The authors declare that they have no competing interests.

\section{Acknowledgements}

We thank all participants in the expert and pilot panel for their contribution to the video vignettes development. This study was supported by the Dutch Cancer Society (Grant number: UVA 2008-4015).

\section{REFERENCES}

[1] Inui TS, Carter WB. Problems and prospects for health-services research on provider patient communication. Med Care 1985;23:521-38.

[2] Ong LML, Visser MRM, Lammes FB, Haes de JCJM. Doctor-patient communication and cancer patients' quality of life and satisfaction. Patient Educ Couns 2000;41:145-56.

[3] Hall JA. Some observations on provider-patient communication research. Patient Educ Couns 2003;50:9-12.

[4] Roter DL, Hall JA, Katz NR. Relations between physicians behaviors and analog patients satisfaction, recall, and impressions. Med Care 1987;25:437-51.

[5] Harrigan JA, Rosenthal R. Physicians head and body positions as determinants of perceived rapport. J Appl Soc Psychol 1983;13:496-509.

[6] Johnson CG, Levenkron JC, Suchman AL, Manchester R. Does physician uncertainty affect patient satisfaction? J Gen Intern Med 988;3:144-9.

[7] Willson P, Mcnamara JR. How perceptions of a simulated physician-patient interaction influence intended satisfaction and compliance. Soc Sci Med 1982;16:1699-704.

[8] Mast MS, Kindlimann A, Langewitz W. Recipients' perspective on breaking bad news: how you put it really makes a difference. Patient Educ Couns 2005;58:244-51.

[9] Mazor KM, Reed GW, Yood RA, Fischer MA, Baril J, Gurwitz JH. Disclosure of medical errors: what factors influence how patients respond? J Gen Intern Med 2006;21:704-10.

[10] Roberts CA, Aruguete MS. Task and socioemotional behaviors of physicians: a test of reciprocity and social interaction theories in analogue physician-patient encounters. Soc Sci Med 2000;50:309-15.

[11] Gerbert B, Berg-Smith S, Mancuso M, Caspers N, Danley D, Herzig K, et al. Video study of physician selection: preferences in the face of diversity. J Fam Pract 2003;52:552-9.

[12] Saha S, Beach MC. The impact of patient-centered communication on patients' decision making and evaluations of physicians: a randomized study using video vignettes. Patient Educ Couns 2011;84:386-92.

[13] Dowsett SM, Saul JL, Butow PN, Dunn SM, Boyer MJ, Findlow R, et al. Communication styles in the cancer consultation: preferences for a patient-centered approach.

Psychooncology 2000;9:147-56. 
Hillen, M.A., Vliet, L.M. van, Haes, H.C.J.M. de, Smets, E.M.A. Developing and administering scripted video vignettes for experimental research of patient-provider communication. Patient Education and Counseling: 2013, 91(3), 295-309

[14] Floyd M, Lang F, Beine KLB, McCord E. Evaluating interviewing techniques for the sexual practices history - use of video trigger tapes to assess patient comfort. Arch Fam Med 1999;8:218-23.

[15] Swenson SL, Buell S, Zettler P, White M, Ruston D C, Lo B. Patient-centered communication. do patients really prefer it? J Gen Intern Med 2004;19:1079-96.

[16] Fogarty LA, Curbow BA, Wingard JR, McDonnell K, Somerfield MR. Can 40 seconds of compassion reduce patient anxiety? J Clin Oncol 1999;17:371-9.

[17] Porensky EK. Breaking bad news: effect of physician communication on analog patients' response. St. Louis: Washington University; 2010.

[18] Shapiro DE, Boggs SR, Melamed BG, Grahampole J. The effect of varied physician affect on recall, anxiety, and perceptions in women at risk for breast-cancer - an analog study. Health Psychol 1992;11:61-6.

[19] Van Vliet LM, Verheul W, Van der Wall E, Bensing JM. The validity of using analogue patients in practitioner-patient communication research: systematic review and meta-analysis. J Gen Intern Med 2012;27:1528-43.

[20] McKinstry B. Do patients wish to be involved in decision making in the consultation? A cross sectional survey with video vignettes. Br Med J 2000;321:867-71.

[21] Aruguete MS, Roberts CA. Gender, affiliation, and control in physician-patient encounters. Sex Roles 2000;42:107-18.

[22] Aruguete MS, Roberts CA. Participants' ratings of male physicians who vary in race and communication style. Psychol Rep 2002;91:793-806.

[23] Schmidt Mast M, Hall JA, Roter DL. Caring and dominance affect participants' perceptions and behaviors during a virtual medical visit. J Gen Intern Med 2008;23:523-7.

[24] Bradley G, Sparks B, Nesdale D. Doctor communication style and patient outcomes: gender and age as moderators. J Appl Soc Psychol 2001;31:

1749-73.

[25] Hughes R, Huby M. The application of vignettes in social and nursing research. J Adv Nurs 2002;37:382-6.

[26] Poulou M. The role of vignettes in the research of emotional and behavioural difficulties. Emot Behav Diff 2001;6:50-62.

[27] Heverly MA, Fitt DX, Newman FL. Constructing case vignettes for evaluating clinical judgement. Eval Program Plann 1984;7:45-55.

[28] Kim S, Brock D, Prouty CD, Odegard PS, Shannon SE, Robins L, et al. A Webbased team-oriented medical error communication assessment tool: development, preliminary reliability, validity, and user ratings. Teach Learn Med 2011;23:68-77.

[29] Schoenberg NE, Ravdal H. Using vignettes in awareness and attitudinal research. Int J Soc Res Meth 2000;3:63-74.

[30] Lapatin S, Goncalves M, Nillni A, Chavez L, Quinn RL, Green A, et al. Lessons from the use of vignettes in the study of mental health service disparities.

Health Serv Res 2012;47:1345-62.

[31] Johnson B. Using video vignettes to evaluate children's personal safety knowledge: methodological and ethical issues. Child Abuse Neglect 2000;24:811-27.

[32] Gerrards-Hesse A, Spies K, Hesse FW. Experimental inductions of emotional states and their effectiveness - a review. Brit J Psychol 1994;85:55-78.

[33] Palomba D, Stegagno L. Physiology, perceived emotion, and memory: responding to film sequences. In: Birbaumer N, O" hman A, editors. The structure of emotion. Seattle: Hogrefe \& Huber Publishers; 1993. p. 156-67.

[34] Westermann R, Spies K, Stahl G, Hesse FW. Relative effectiveness and validity of mood induction procedures: a meta-analysis. Eur J Soc Psychol 1996; 26:557-80.

[35] Butow PN, Dowsett S, Hagerty R, Tattersall MH. Communicating prognosis to patients with metastatic disease: what do they really want to know? Support Care Cancer 2002;10:161-8.

[36] Mehrabian A. Nonverbal communication. Chicago: Aldine-Atherton; 1972.

[37] Mercer SW, Reynolds WJ. Empathy and quality of care. Brit J Gen Pract 2002;52:S912. 
Hillen, M.A., Vliet, L.M. van, Haes, H.C.J.M. de, Smets, E.M.A. Developing and administering scripted video vignettes for experimental research of patient-provider communication. Patient Education and Counseling: 2013, 91(3), 295-309

[38] Bruun Vaage M. Fiction film and the varieties of empathic engagement. Midwest Stud Philos 2010;34:158-79.

[39] Choi J. Leaving it up to the imagination: POV shots and imagining from the inside. J Aesthetics Art Criticism 2005;63:17-25.

[40] Ruby P, Decety J. How would you feel versus how do you think she would feel? A neuroimaging study of perspective-taking with social emotions. J Cogn Neurosci 2004;16:988-99.

[41] Green MC, Brock TC. The role of transportation in the persuasiveness of public narratives. J Pers Soc Psychol 2000;79:701-21.

[42] Hall JA, Harrigan JA, Rosenthal R. Nonverbal behavior in clinician patient interaction. Appl Prev Psychol 1995;4:21-37.

[43] Lench HC, Flores SA, Bench SW. Discrete emotions predict changes in cognition, judgment, experience, behavior, and physiology: a meta-analysis of experimental emotion elicitations. Psychol Bull 2011;137:834-55.

[44] Atzmuller C, Steiner PM. Experimental vignette studies in survey research. Methodology 2010;6:128-38.

[45] Van Vliet LM, Hillen MA, Van der Wall E, Plum N, Bensing JM. How to create and administer scripted video-vignettes in an experimental study on disclosure of a palliative breast cancer diagnosis. Patient Educ Couns 2012. http://

dx.doi.org/10.1016/j.pec.2012.10.017 [Epub ahead of print 6 Dec 2012].

\section{TABLES AND FIGURES}

Research phase

Phase I:

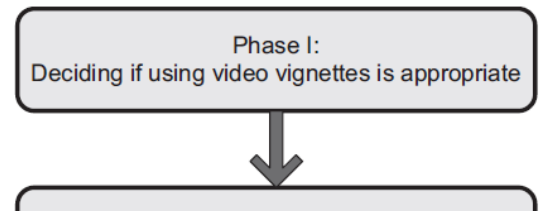

Phase II:

Developing a valid script

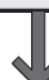

Phase III:

Designing valid manipulations

Phase IV

Converting the scripted consultation to video

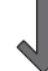

Phase V:

Administering the videos

\section{Methodological dilemmas}

1. The background of the script: based on literature or real interactions

The proportion of the consultation scripted: whole or abridged consultation

Establishing realism: which experts to consult at which stages

4. Developing an introduction: video, written or audio introduction

Operationalizing manipulations: consulting experts, determining how many levels per manipulation The verbal and/or nonverbal nature of the manipulations: only (non)verbal or both . Compensating for duration differences: using fillers or retaining duration differences

Choosing appropriate actors: using professional actors or clinicians Determining the camera perspective: showing both patient and clinician or only the clinician Pilot-testing the videos: at which stage, using which pilot participants

Fig. 1. Visual display of the methodological issues encountered in all phases of conducting experimental research using video vignettes. 
Table 1

Overview of experimental studies of communication in health care using video vignettes and their methodological approach.

\begin{tabular}{|c|c|c|c|c|c|c|c|}
\hline \multirow[t]{2}{*}{ Author, year, country } & \multirow[t]{2}{*}{$\begin{array}{l}\text { Communication } \\
\text { variables } \\
\text { manipulated }\end{array}$} & \multirow[t]{2}{*}{ 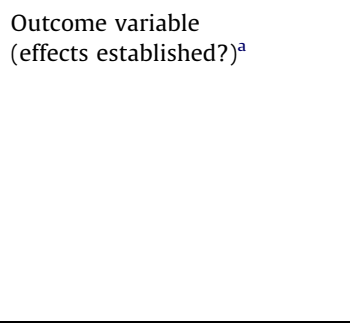 } & $\begin{array}{l}\text { Phase I: deciding if using } \\
\text { video vignettes is } \\
\text { appropriate }\end{array}$ & $\begin{array}{l}\text { Phase II: developing } \\
\text { a valid script }\end{array}$ & $\begin{array}{l}\text { Phase III: } \\
\text { designing valid } \\
\text { manipulations }\end{array}$ & $\begin{array}{l}\text { Phase IV: converting } \\
\text { scripted consultation } \\
\text { to video }\end{array}$ & $\begin{array}{l}\text { Phase V: administering } \\
\text { the videos }\end{array}$ \\
\hline & & & $\begin{array}{l}\text { Motivation for using } \\
\text { vignettes }\end{array}$ & $\begin{array}{l}\text { 1. The background } \\
\text { of the script } \\
\text { 2. The proportion of } \\
\text { the consultation scripted } \\
\text { 3. Consulting experts } \\
\text { 4. Developing } \\
\text { an introduction }\end{array}$ & $\begin{array}{l}\text { 1. Operationalizing } \\
\text { manipulations } \\
\text { 2. The verbal/nonverbal } \\
\text { nature of } \\
\text { manipulations } \\
\text { 3. Compensating for } \\
\text { duration differences }\end{array}$ & $\begin{array}{l}\text { 1. Choosing } \\
\text { appropriate actors } \\
\text { 2. Determining camera } \\
\text { perspective } \\
\text { 3. Pilot-testing the } \\
\text { videos }\end{array}$ & $\begin{array}{l}\text { 1. Choosing viewers } \\
\text { 2. Arrangement of } \\
\text { the setting } \\
\text { 3. Determining number } \\
\text { of videos per viewer } \\
\text { 4. Informing and/or } \\
\text { debriefing viewers }\end{array}$ \\
\hline $\begin{array}{l}\text { Aruguete and Roberts, } \\
2000 \text {, USA }\end{array}$ & $\begin{array}{l}\text { Affiliative and } \\
\text { controlling } \\
\text { consultation style }\end{array}$ & $\begin{array}{l}\text { - Satisfaction + } \\
\text { - Trust + } \\
\text { - Self-disclosure + } \\
\text { - Willingness to recommend + } \\
\text { - Compliance + } \\
\text { - Recall = }\end{array}$ & $\begin{array}{l}\text { One aspect of the } \\
\text { interaction can be } \\
\text { isolated and } \\
\text { manipulated }\end{array}$ & $\begin{array}{l}\text { 1. Not reported } \\
\text { 2. Videos lasted } 5 \mathrm{~min} \text {. No } \\
\text { report of content } \\
\text { 3. Not reported } \\
\text { 4. Not reported }\end{array}$ & $\begin{array}{l}\text { 1. Consultation style } \\
\text { (affiliative vs. } \\
\text { controlling). } \\
\text { Operationalization } \\
\text { included differences on } 5 \\
\text { behavioral dimensions. } \\
\text { No report of } \\
\text { operationalization or } \\
\text { manipulation basis } \\
\text { 2. Both verbal and } \\
\text { nonverbal } \\
\text { 3. Not reported }\end{array}$ & $\begin{array}{l}\text { 1. Actors played the } \\
\text { patient and physicians } \\
\text { 2. Not reported } \\
\text { 3. Not reported }\end{array}$ & $\begin{array}{l}\text { 1. Psychology students. } \\
\text { Not motivated. } \\
\text { 2. Not reported } \\
\text { 3. One video per } \\
\text { participant } \\
\text { 4. Beforehand, the } \\
\text { study was described as } \\
\text { investigating } \\
\text { physician-patient } \\
\text { communication. } \\
\text { Debriefing afterward } \\
\text { not reported }\end{array}$ \\
\hline $\begin{array}{l}\text { Araguete and Roberts, } \\
\text { 2002, USA }\end{array}$ & Nonverbal behavior & $\begin{array}{l}\text { - Satisfaction + } \\
\text { - Trust + } \\
\text { - Self-disclosure + } \\
\text { - Willingness to recommend + } \\
\text { - Compliance + } \\
\text { - Recall + }\end{array}$ & $\begin{array}{l}\text { Increased internal } \\
\text { validity can be } \\
\text { achieved }\end{array}$ & $\begin{array}{l}\text { 1. Not reported } \\
\text { 2. Videos lasted } 7 \text { min. Each } \\
\text { video covered history } \\
\text { taking, diagnosis, } \\
\text { prescribing medication, } \\
\text { prognosis, complications, } \\
\text { and follow-up } \\
\text { 3. Not reported } \\
\text { 4. Not reported }\end{array}$ & $\begin{array}{l}\text { 1. Nonverbal behavior } \\
\text { (expressing concern or } \\
\text { distance). Manipulation } \\
\text { involved differences on } 5 \\
\text { behavioral dimensions, } \\
\text { e.g., eye contact, distance } \\
\text { to the patient. No report } \\
\text { of operationalization or } \\
\text { manipulation basis } \\
\text { 2. Only nonverbal } \\
\text { 3. Not reported }\end{array}$ & $\begin{array}{l}\text { 1. Actors played the } \\
\text { patient and physicians } \\
\text { 2. The camera was } \\
\text { positioned over the } \\
\text { patient's shoulder and } \\
\text { focused at the } \\
\text { physician } \\
\text { 3. Not reported }\end{array}$ & $\begin{array}{l}\text { 1. Patients from a } \\
\text { waiting room of a } \\
\text { student outpatient } \\
\text { clinic. Not motivated } \\
\text { 2. Observation in } \\
\text { private. Setting not } \\
\text { described } \\
\text { 3. One video per } \\
\text { participant } \\
\text { 4. Beforehand, the } \\
\text { study was described as } \\
\text { investigating } \\
\text { physician-patient } \\
\text { communication. } \\
\text { Debriefing afterward } \\
\text { not reported }\end{array}$ \\
\hline $\begin{array}{l}\text { Bradley et al., } \\
\text { 2001, Australia }\end{array}$ & $\begin{array}{l}\text { Authoritative and } \\
\text { consultative } \\
\text { communication styles }\end{array}$ & $\begin{array}{l}\text { - Satisfaction + } \\
\text { - Adherence = } \\
\text { - Recall = }\end{array}$ & $\begin{array}{l}\text { Ratings can be made } \\
\text { independently of } \\
\text { confounding factors (e.g., } \\
\text { previous exposure to the } \\
\text { doctor) }\end{array}$ & $\begin{array}{l}\text { 1. Scripts based on informal } \\
\text { focus groups and advice } \\
\text { from a medical practitioner } \\
2 \text {. Videos lasted } 3 \text { min. No } \\
\text { report of content } \\
\text { 3. University students, } \\
\text { laypeople and health } \\
\text { professionals commented } \\
\text { on script similarity, } \\
\text { credibility, manipulation } \\
\text { success, medical content } \\
\text { 4. Written introduction of } \\
\text { the scenario }\end{array}$ & $\begin{array}{l}\text { 1. Communication style } \\
\text { (authoritative vs. } \\
\text { Consultative). } \\
\text { Operationalizations } \\
\text { differed on five } \\
\text { characteristics. } \\
\text { Manipulations based on } \\
\text { literature review } \\
\text { 2. Not reported } \\
\text { 3. Approximately same } \\
\text { length. }\end{array}$ & $\begin{array}{l}\text { 1. Professional actors } \\
\text { played the patient and } \\
\text { physician roles } \\
\text { 2. Not reported } \\
\text { 3. Pilot-testing } \\
\text { conducted only on the } \\
\text { scripts (see Section } \\
\text { 3.2.3) }\end{array}$ & $\begin{array}{l}\text { 1. Healthy adults } \\
\text { ranging from } 17 \text { to } 84 \\
\text { years. Not motivated } \\
\text { 2. Observation in } \\
\text { groups (up to } 30 \\
\text { subjects), participants } \\
\text { were instructed not to } \\
\text { converse. Setting not } \\
\text { described } \\
\text { 3. One video per } \\
\text { participant } \\
\text { 4. Participants were } \\
\text { debriefed after } \\
\text { participation, not } \\
\text { further specified }\end{array}$ \\
\hline
\end{tabular}


Communication

variables
Outcome variable

(effects established?
Phase I: deciding if using

video vignettes is

appropriate

Motivation for using

vignettes
Dowsett et al., 2000,

Australia

Patient-centered and

doctor-centered

communication

- Preference +

Sarsfaction +1
- Anxiety +

- Recall -

- Physician rating +

- Treatment decision $=$

None

Fogarty et al
1999, USA

Compassion
1. Scripts based on audiotaped consultations between two medical

oncologists an
Phase II: developing

1. The background

of the script

. The proportion of

the consultation scripted
3. Consulting experts

3. Consulting expert

an introduction

Phase III:

manipulations

2. The verbal/

nature of

manipulations duration differences

\section{Communication style}

\section{Not reported}

scores

- APs can compare and

contrast different styles directly

ach video covered prognosis.

3. Not reported

4. Not reported

(doctor-centered vs.

Operationalizations

11 behavioral

dimensions. patient-centered).

real consultation but

Floyd et al.,

Physician's interview

approach to

Level of comfort +

None
1. Operationalizing

. The verbal/nonverbal

. Compensating for

diagnosis, treatment, and

Manipulations based on

literature review,

observations, interviews

with patients

2. Both verbal and

nonverbal

3. Not reported

1. Expression of

their patients enhanced compassio

enhanced).

2 . Videos lasted $18-19 \mathrm{~min}$; included 2 added

they were shorter than a

contained the same basic

information

3. Not reported

4. Not reported

segments (involving

acknowledging conce

expressing support,

validation of emotion

state, hand-touching, and appropriateness for the reassuring). No report of intended audience

manipulation basis

2. Both verbal and

nonverbal

3. 40-s duration

difference. No

compensation

Phase IV: converting Phase V: administering

scripted consultation the videos

video

1. Choosing

1. Choosing viewers Determining camera the setting

perspective 3. Determining numbe

videos 4 . Informing and/or 4. Informing and/or
debriefing viewers

\section{Professional actors 1. Breast cancer}

played the patient and survivors and their

physician healthy relatives and

2. Not reported friends. Not motivated

2. Not reported

3. Two videos (patient-

centered and doctor-

centered) per

participant. Each

participant first saw

both versions of the

diagnosis, then of the

treatment, and finally

of the prognosis

4. Not reported

1. An oncologist played 1. Both breast cancer the physician, a healthy survivors and healthy woman played the women, because of patient possible different

2. Not reported hypothetical decision

3. Four focus groups ( 2 making between the with healthy women, 2 two groups and

with breast cancer because using survivor because using survivors more generalizable more generalizable $\begin{array}{lll}\text { 1. Not reported } & \text { 1. Interview technique. } & \text { 1. Not reported } \\ \text { 2. No report of duration or } & \text { Operationalization } & \text { 2. Not reported }\end{array}$ $\begin{array}{lll}\text { 2. No report of duration or } & \begin{array}{l}\text { Operationalization } \\ \text { included five areas of the }\end{array} \\ \text { content } & \text {. Videos were }\end{array}$

3. Not reported interview, encompassing evaluated by an 2 or 3 possible independent panel of recommended consultants in the techniques for each area. clinical interviewing No further report of

field

operationalization and

manipulation bias

2. Not reported groups, were instripants converse sed not to described 3. One video per participant 4. Not reported

1. Healthy students and seniors. Not motivated 2. Observation in groups. Setting not described 3. All videos were observed by all participants 4. Not reported 
APs can compare an physicians directly
Empathy + behavio

resen and 1983, USA

One aspect of the

interaction can be isolated 2 . Videos lasted $7 \mathrm{~min}$. No and manipulated

Full disclosure, an existing - Changing physicians +

positive relationship Seeking legal advice + -

2006, USA report of conten

3. Not reported

4. Not reported

1. Scripts based on

literature on the

2. Videos lasted $45 \mathrm{~s}$, and

included a short health

3. Not reported

4. Physicians introduced

camera

Not reported

. Videos lasted $12 \mathrm{~min}$

of 30 s). No report of

content

No introduction, but 4

'practice trials' to acquin

procedure

1. Not reported
2. Not reported
3. Not reported
4. Not reported

4. Not reported
None - Trust +

severity of clinical

outcomes of a medical error - Emotional response + /-
1. Gender (male vs. female) and ethnicity

(African American,

American). established by using different actors

2. Only nonverbal

3. No duration differences
Operationalization

Actors played the 1 . Healthy people physicians. They were visiting a shopping similar in age and mall. Not motiva attractiveness 2. Not reported 2. The physician gazed 3 . All 5 videos observed directly into the by all participants camera. No patient was 4. Not reported visible or audible 3. Not reported

1. Nonverbal behaviors: trunk angle (forward, straight, or backward) arm position (open vs. folded), leg position open vs. crossed). No report of

operationalization and manipulation basis

2. Only nonverbal; all

3. Not reported

1. Four family medicine 1 . Introductory esidents played the psychology students. physicians Not motivated 2. Actors were recorded 2 . Not reported at an angle of $45^{\circ} \quad 3$. Two videos per orientation toward the participant, each video camera, facing the consisted of 24 short simulated patient. Only (30s) video segments the patient's legs and 4. Not reported feet were visible so that patient was

3. Not reported

1. Physician response to 1 . Not reported uncertainty (no $\quad 2$. Not reported acknowledgment, 3. Not reported avoidance, uncertainty textbol, or consulting textbook, or consulting computer). No report of
operationalization and manipulation basis 2. Both verbal and nonverbal

3. Approximately same length

1. Medication error type 1 Not $\begin{array}{ll}\text { (missed allergy vs. } & 2 \text {. Not reported }\end{array}$ inadequate monitoring), 3. Not reported outcome (life threatening vs. less serious), physician disclosure (full vs. nondisclosure), costs handling (offer to waive costs vs. no reference to costs), prior positive relationship (yes vs. no) Operationalization partly by variations in physicly by variations in physician by information, partly by information through voice-over. No report
manipulation basis

2. Not reported

3. Not reported
1. Patients awaiting their appointment in a medical clinic. Not motivated

2. Not reported 3. One video
participant 4. Not reported

1. Health plan members. No motivated 2. Observation in private. Setting not described 3. One video per participant 4. Beforehand, the study was described as focusing on doctorpatient communicatio about medical errors. not reported patient communication 
Communication

variables

manipulated
Outcome variable

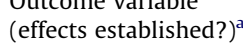

Shared or directed

approach of decision

making

Preference +

McKinstry,
2002, UK

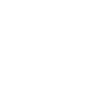

Porensky, 2010, USA (PhD Thesis)
Forecasting bad news and - Psychological distress + /framing prognostic $\quad-$ Recall $=$

information - Prognosis interpretation +
Phase I: deciding if using

video vignettes is

appropriate

Motivation for using vignettes

Phase II: developing
a valid script
1. The background
of the script
2. The proportion of
the consultation scripted
3. Consulting experts
4. Developing
an introduction

Phase III:

designing valid

manipulations

1. Operationalizing

manipulations

2. The verbal/nonverbal

nature of

manipulations

3. Compensating for duration differences

Phase IV: converting

scripted consultation

to video

1. Choosing

appropriate actors

2. Determin

perspective

videos

1. Decision making style 1 . Not reported

1. Not reported

(directed vs. shared), in 2. Not reporte

2. No report of duration. (directed vs. shared), in

decision making part of the No report of

1. Adult patients an
parents of children

consultatio

operationalization,

3. Not reported although scripts for both test manipulation

4. Introduction including a styles displayed in paper, success

brief description of the no report of manipulation

history (not further

basis

specified)

2. Not reported

3. Shared versions were

longer, not further

specified. No report of

compensation

1. Information provided in 1 . Warning before diagnosis (yes vs. no)

- One aspect of the and manipulated

script was based on diagnosis (yes vs. no),

oncologic liter

- Patient outcomes can be accordance with

assessed directly after the

(positive vs. negative)

Operationalization of the

warning condition

delivering bad news

warning condition

2. Each video covered only the diagnosis $(2 \mathrm{~min})$ and one extra statement ('I'm
prognosis $(2 \mathrm{~min})$ parts of a afraid I have bad news'. (trid I have bad news', the video. Videos were experiment room, on a consultation

3. Not reported making eye contact with

patient]. Prognosis

the situation and medical history

framing manipulated

two sentences with

1. A physician played

Phase V: administering

the physician

2. The physician

1. Choosing viewers

2. Arrangement of

the setting

3. Determining number

of videos per viewer

ing and/or

1. Adult patients and

visiting general

practices. Not

2. Observation in small groups (max. 4 patients at same time). Setting not described

3. Two videos (shared

and directed) per

participant

4. Not reported

reversed framing. No

report of manipulation

basis

2. Mostly verbal, but

slight nonverbal aspect

(i.e. eye contact in

warning condition)

3. Approximately same

length 

and manipulated

1. Not reported

1. Socioemotiona Videos lasted $7 \mathrm{~min}$. E video covered diagnosis, prognosis, medication prescription, and life style recommendation 3. Not reported 4. Not reported

(is

(high vs. low),

low). Manior (high vs.

included several . questions). Manipulation

explaining the need for

more definitive tests,

discussing the etiology,

and inquiring about

common physiological

and behavioral

symptoms. No report of

2. Both verbal and

nonverbal

3. Not reported

1. Not reporte

1. Patient-centered was a white, 60-year- student health clinic. old, male 2 . The appearance and 2 . Observation in dialog of the patient private. Videos were physician appeared to distraction irectly to the observer, 3. One video per focilitate participant participant 2. Videos lasted between 4 communication (high vs. played the patients disease diagnosis or at and $5 \mathrm{~min}$ and $20 \mathrm{~s}$. No low). Operationalization (male and female) and risk, to ensure that the of high PCC based on two physicians. The videos were of

3. Experts (patients, health core elements: physicians wore scrubs, relevance to them white coats and $\begin{array}{lll}\text { accuracy of script content partnered approach, and } & \text { professional director } \\ \text { and realism of dialog in } & \text { specific associated } & \text { ensured }\end{array}$ and realism of dialog, in multiple iterations 4. Written introduction behaviors. Manipulati based on aspects covering brief description mentioned in literature nonverbal: nonverbal
behaviors reinforced standardization of behaviors between introductory scree verbal behaviors actors ehaviors recorded using the decision making about the patient not reported longer. No compensation; was not seen, to altering dialog pace to facilitate participants compensate for the to assume the role of difference resulted in less the patient.

realistic takes 3. Not reported 
Phase I: deciding if using

video vignettes is

appropriate

Motivation for using

vignettes

\section{Schmidt Mast \\ et al., 2005 , \\ Switzerland}

$\begin{array}{ll}\text { Patient-, disease-, and } & \text { - Satisfaction }+ \\ \text { emotion-centered } & \text { - Perception of physician }+ \\ \text { communication } & \text { - Mood }+/-\end{array}$

$\begin{array}{ll}\text { emotion-centered } & - \text { Perception of physician }+ \\ \text { communication } & - \text { Mood }+/-\end{array}$
None

Worried or nonworried

communication style
- Anxiety +
- Recall +
- Peceived
Phase II: developing

a valid script

1. The background

of the script

2. The proportion of

the consultation scrip

4. Developing

an introduction

2. Videos lasted between

and 11 min. Each video

treatment discussion

3. Not reported

4. Not reported

Phase III:

designing vali

manipulations

1. Operationalizing

manipulations

2. The verbal/nonverbal

mature of

manipulations

3. Compensating for

1. Consultation style

(patient-, disease-,

emotion-centered).

Operationalization

involved providin

information and

emotional support

according to the patient's
needs (patient-centered)

needs (patient-cente
providing medical

information to the

physician's standard

(disease-centered) or

dealing explicitly with

sadness and anxiety

(emotion-centered).

Script examples provided

in the paper. No report of

manipulation basis

2. Not reported

3. Not reported

et al., 1992,

USA
Avoiding ethical problems 1 . Information provided in 1. Presentation of

that would arise when

varying communicatio clinical care

ambiguous

\section{script based on oncology \\ literature \\ 2. Videos lasted $4 \mathrm{~min}$. No} report of conten

4. Read-aloud introduction describing the situatio mammography results

1. Not reported

2. Not reported

(worried vs. nonworried). testing (with 22

women) to assess

realism, and ability to

anxious appearance of

physicians, repeatedly

saying 'I am worried'
(worried condition) or

(worried condition)
calm and relaxed

calm and relaxed
appearance, repeatedly

ability to watched on a large

situation described

television monito

3. One video per

participant

saying 'I am not

(nonworried condition).

No report of

manipulation basis

2. Both verbal and

nonverbal

3. Not reported 


\section{- Compliance +1 -}

Less skewed distributions 1 . Scripts based on interaction can be and manipulated interviews with physician and manipulated communication experts 2. Videos lasted 2-3 min. No report of content 3. Not reported 4. Not reported

Avoiding ethical problems that would arise when varying com
clinical care
1. Physician communication style (bionse to CAM use (biomedical vs. patiententered) Operationalization of the patient-centered style involved developing an understanding of the patient as a person, conveying empathy

finding common ground.

Manipulations based on

interviews with

physicians and empirica

centered communicatio

2. Not reported

2. Not reported

3. Patient-centered

versions were longer

(mean 16s). Duration

differences minimize

but not compensated
1. Not reported 1. Courtesy (highly

courteous vs. relative inconsiderate) and competence (highly competence (high
less competent) less competent). Operationalization of
courtesy involved 18 4. No introduction of situation, but rolecourtesy involved 18 the video) previous research.
1. Professional actors 1. Patients at urgen payed the patients and care and general $\begin{array}{ll}\text { physicians } & \text { internal medicine } \\ \text { 2. Not reported } & \text { clinics. Not motivat }\end{array}$ $\begin{array}{ll}\text { 2. Not reported } & \text { clinics. Not motivatidual pilot- } \\ \text { 3. Ind reported }\end{array}$ testing (with $10 \quad 3$. Two videos physicians in general (biomedical and internal medicine) to patient-centered) per assess the videos' face participant validity

4. Not reported
1. Actors played the 1. Healthy psychology patient, physician and students. Not nurse

2. Not reported

3. Individual pilot-

testing (with 28

students) to assess not described 2. Observation in small groups (8-15 participants). Settin Operationalization of competence involved showing all or only a selection of 18 behaviors technical behaviors described in guidelines. described in guidelines. previous study and previous study and
physician guidelines 2. Both verbal and nonverbal participant study was described as focusing on 'consumer perceptions'. Debriefing afterward not reported

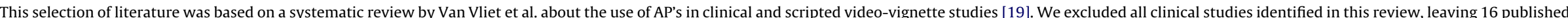

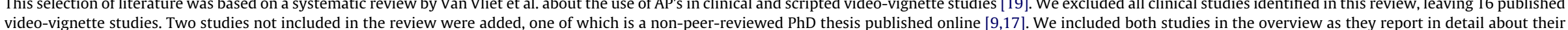
methodology, and could therefore be illustrative to the reader. For a more elaborate study description and review of the studies below, we refer to Van Vliet et al. [19].

a '+' indicates significant effects, ' $=$ ' indicates no significant effects, ' $+l-$ ' indicates significant effects for part of the manipulations

b Studies not included in the review by Van Vliet et al. 
Table 2

Overview of the methodological literature on the development and use of vignettes.

\begin{tabular}{|c|c|c|c|}
\hline Author, year, country & Field of study & Types of vignettes & Short description \\
\hline Heverly et al., 1984, USA & Medicine; clinical judgment & Written & $\begin{array}{l}\text { Stepwise description of methodological } \\
\text { problems encountered when } \\
\text { developing case vignettes. Focus on } \\
\text { developing multiple (non- } \\
\text { communication) manipulations }\end{array}$ \\
\hline Hughes, 2002, UK & Social and nursing research & $\begin{array}{l}\text { All types (both } \\
\text { written and video) }\end{array}$ & $\begin{array}{l}\text { Consideration of both the advantages } \\
\text { and the pitfalls of using vignettes, most } \\
\text { importantly external validity }\end{array}$ \\
\hline Kim et al., 2011, USA & Medicine; medical communication assessment & Video & $\begin{array}{l}\text { Stepwise elaborate description of } \\
\text { vignettes development }\end{array}$ \\
\hline Lapatin et al., 2012, USA & Medicine; health disparities research & Written & $\begin{array}{l}\text { Stepwise elaborate description of } \\
\text { vignettes development }\end{array}$ \\
\hline Schoenberg and Ravdal, 2000, USA & Social research; attitudes and awareness & Written & $\begin{array}{l}\text { Elaborate description of vignettes } \\
\text { development, focus on advantages and } \\
\text { difficulties }\end{array}$ \\
\hline
\end{tabular}


Hillen, M.A., Vliet, L.M. van, Haes, H.C.J.M. de, Smets, E.M.A. Developing and administering scripted video vignettes for experimental research of patient-provider communication. Patient Education and Counseling: 2013, 91(3), 295-309

A. Only point-of-view angle facing care provider.

B. Alternating viewpoints
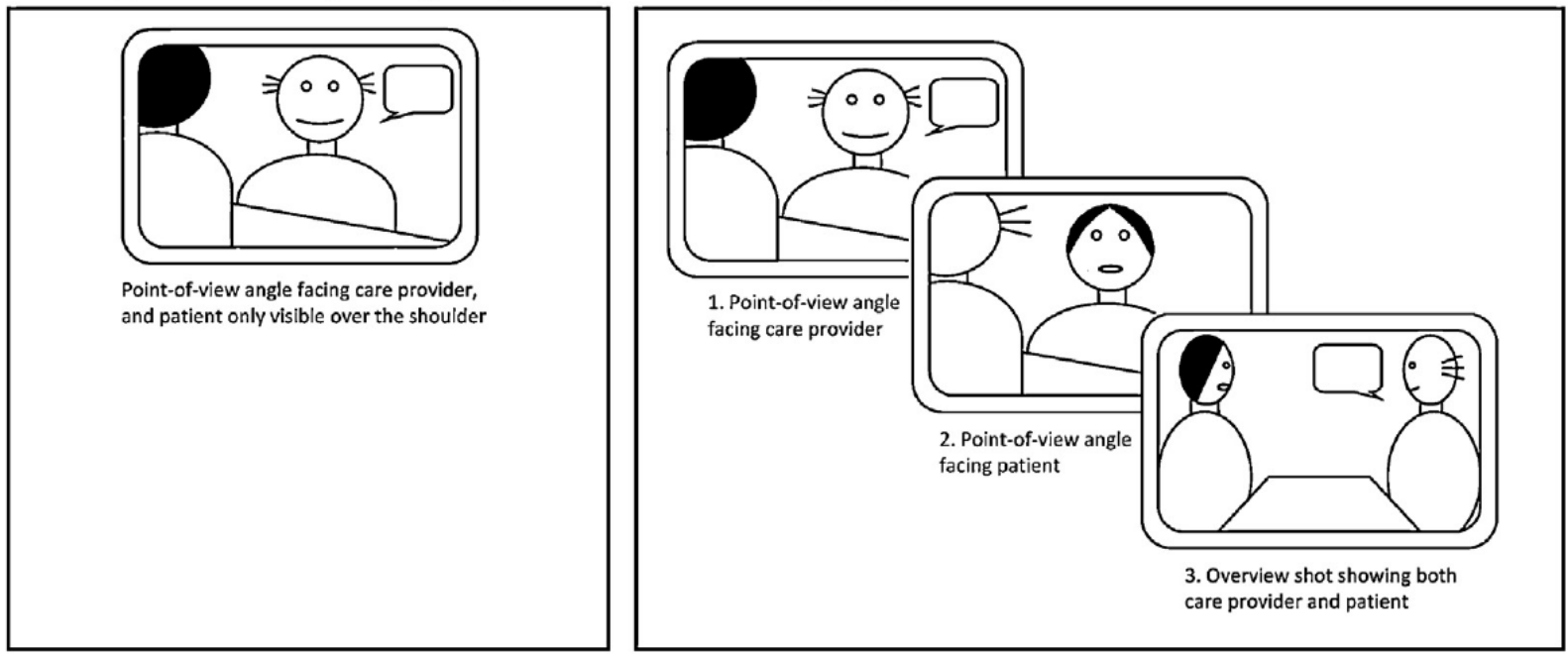

Fig. 2. Schematic display of two alternative approaches to camera perspectives. 